\title{
Importance of Antiserum and Phagocytic Cells in the Protection of Mice Against Infection by Klebsiella pneumoniae
}

\author{
By TAKERO FUKUTOME, * MASAO MITSUYAMA, \\ KENJI TAKEYA AND KIKUO NOMOTO \\ Departments of Microbiology and Immunology, School of Medicine, Kyushu \\ University, Higashi-Ku, Fukuoka, 812 Japan
}

(Received 1 November 1979; revised 22 January 1980)

\begin{abstract}
Rabbit antiserum to Klebsiella pneumoniae showed a powerful protective effect against intramuscular infection in normal mice. No protective effect was observed in mice whose monocytes and polymorphonuclear cells were depleted by $\mathrm{X}$-irradiation. The antiserum had approximately the same protective effect in mice whose macrophages were blocked selectively by carrageenan as in normal mice. It is concluded that antiserum exerted its effect by opsonic function and that opsonized $K$. pneumoniae were eliminated mainly by polymorphonuclear cells rather than macrophages, at least in an early phase of the infection. These findings were supported by histological examination and observation of intracellular killing in vitro.
\end{abstract}

\section{INTRODUCTION}

Klebsiella species are opportunist pathogens (Dreizen et al., 1974) causing, for example, infections of the respiratory and urinary tracts (Graybill et al., 1973; Lorian \& Topf, 1972). Specific antiserum plays an important role in protection against some encapsulated bacteria such as Klebsiella pneumoniae (Julianelle, 1926), but the involvement of cells in eliminating these bacteria remains undetermined.

Phagocytic cells contribute in different degrees and at different stages of infection to protection against many micro-organisms. For example, the final effector cells against Listeria monocytogenes are macrophages (Mitsuyama et al., 1978; Tatsukawa et al., 1979), whilst $P$ seudomonas aeruginosa is killed effectively by both polymorphonuclear cells (PMN) and macrophages (Van Furth et al., 1978; Tatsukawa et al., 1979).

In the present study, $K$. pneumoniae was chosen as a typical encapsulated Klebsiella species and the cells involved in the protection of mice were analysed in the presence of rabbit anti-K. pneumoniae serum.

$\mathrm{X}$-irradiation was used to deplete the population of all phagocytes except tissue macrophages and carrageenan was used to deplete mononuclear phagocytes selectively (Catanzaro et al., 1971). To facilitate the analysis, the susceptibility of $K$. pneumoniae to phagocytes was compared with that of $P$. aeruginosa.

\section{METHODS}

Animals. Outbred female CF1 mice were obtained from the Breeding Unit of Experimental Animals, Kyushu University, Japan. Athymic nude mice (nu/nu) of BALB/c background and their normal littermates $(\mathrm{nu} /+)$ were obtained from the Kyudo Laboratory for Experimental Animals, Kumamoto, Japan. Mice were used for experiments when 6 to 10 weeks old. Rabbits of both sexes, all weighing about $3 \mathrm{~kg}$, were obtained from a local breeder. 
Micro-organisms. Pseudomonas aeruginosa was isolated from the sputum of a patient suffering from acute pneumonia. Capsulated Klebsiella pneumoniae strain Fu-1 has been maintained in our laboratory. Microorganisms were cultured overnight in Tryptic Soy Broth (Difco) at $37^{\circ} \mathrm{C}$ for use in experiments. The $\mathrm{LD}_{50}$ of $P$. deruginosa for mice by the intravenous route was approximately $1 \times 10^{7}$ viable bacteria (Tatsukawa et al., 1979). Out of 10 mice, only two survived $14 \mathrm{~d}$ after intramuscular inoculation of 10 viable $\mathrm{K}$. pneumoniae.

Antiserum. In our preliminary experiments, mice immunized with $K$. pneumoniae produced antiserum with a low titre for agglutination which was inconvenient to use for experiments. A rabbit was therefore immunized subcutaneously with $6 \times 10^{9}$ formalin-killed $K$. pneumoniae in complete Freund's adjuvant. A week later, the rabbit was immunized intraperitoneally with $3 \cdot 8 \times 10^{8}$ viable $K$. pneumoniae. Ten days after the second immunization, the rabbit was bled and about $50 \mathrm{ml}$ of serum was removed from the clotted blood. Normal serum was obtained from three rabbits. The sera were heat-inactivated at $56{ }^{\circ} \mathrm{C}$ for $30 \mathrm{~min}$ and stored in $1 \mathrm{ml}$ portions at $-70^{\circ} \mathrm{C}$. A suspension of about $7 \times 10^{8} \mathrm{~K}$. pneumoniae $\mathrm{ml}^{-1}$ showed satisfactory agglutination with antiserum diluted to $1 / 64$ with phosphate-buffered saline (PBS), but no agglutination occurred with normal serum.

Determination of bacterial growth in mice. Mice were inoculated intramuscularly into the middle of the right thigh with $1 \times 10^{5}$ viable $P$. aeruginosa or $1 \times 10^{4}$ to $1 \times 10^{5}$ viable $K$. pneumoniae suspended in Hanks' balanced salt solution (HBSS). At various times after inoculation, the whole muscle mass of an infected thigh was removed and homogenized in $10 \mathrm{ml}$ PBS with a Teflon and glass homogenizer. Suspensions were diluted 10-fold serially with PBS and 0.1 or $1.0 \mathrm{ml}$ of each dilution was spread on nutrient agar. Colonies were counted after incubation at $37^{\circ} \mathrm{C}$ for $20 \mathrm{~h}$ ( $P$. aeruginosa) or $15 \mathrm{~h}$ (K. pneumoniae).

By $4 \mathrm{~h}$ after intravenous inoculation of $K$. pneumoniae in mice, the bacteria had grown as well in the liver, spleen, lungs and kidneys as in the blood, but at $24 \mathrm{~h}$ bacterial growth was greater in the liver than in the other organs (unpublished results). Therefore, to observe the systemic spread of bacteria after intramuscular inoculation, bacteria were counted in the liver and blood. Mice were bled by cutting the femoral artery and the blood was diluted and plated as described above. Livers were removed, homogenized and counted as described above.

Treatment of mice with antiserum. The heat-inactivated antiserum or normal serum was diluted 20-fold with PBS and injected intraperitoneally in a volume of $1 \mathrm{ml} 60 \mathrm{~min}$ before inoculation of $K$. pneumoniae.

$X$-irradiation. Mice were exposed to $8 \mathrm{~J} \mathrm{~kg}^{-1}(800 \mathrm{rad})$ whole body $\mathrm{X}$-irradiation and infected $2 \mathrm{~d}$ later. The radiation was delivered from a Shimadzu $250 \mathrm{kV}$ machine (Shimadzu, K. K., Tokyo, Japan) operating at $200 \mathrm{kV}$ with $0.3 \mathrm{~mm} \mathrm{Cu}$ and $1 \mathrm{~mm} \mathrm{Al} \mathrm{filtration} \mathrm{at} 100 \mathrm{~cm}$ from the target focus.

Carrageenan. Carrageenan type II (Sigma) was dissolved in distilled water and injected intraperitoneally (200 $\left.\mathrm{mg} \mathrm{kg}^{-1}\right) 24 \mathrm{~h}$ before infection.

Phagocytosis and intracellular killing in vitro. PMN were washed out from the peritoneal cavity with HBSS $3 \mathrm{~h}$ after injection of $2 \mathrm{ml} 0.2 \%(\mathrm{w} / \mathrm{v})$ sodium caseinate; the suspension contained about $80 \% \mathrm{PMN}$. Macrophages were harvested from the peritoneum $3 \mathrm{~d}$ after injection of $2 \mathrm{ml} 10 \%(\mathrm{w} / \mathrm{v})$ proteose-peptone (Difco); about $75 \%$ of the cells were macrophages.

Cell suspensions were washed three times with HBSS and resuspended at $2 \times 10^{7} \mathrm{cells} \mathrm{ml}^{-1}$ in HBSS containing $0.1 \%(\mathrm{w} / \mathrm{v})$ gelatin and $10 \%(\mathrm{v} / \mathrm{v})$ fresh autologous serum. The viability of the suspended cells, checked by dye exclusion of Trypan Blue, was over $98 \%$. Cell suspensions $(1.5 \mathrm{ml})$ were mixed with equal volumes of bacterial suspensions containing $2 \times 10^{7}$ bacteria $\mathrm{ml}^{-1}$ and incubated at $37^{\circ} \mathrm{C}$ for 15 min to allow phagocytosis to occur. For K. pneumoniae, but not for $P$. aeruginosa, normal rabbit serum or antiserum was added to the cell suspension to obtain a final concentration of $5 \%(\mathrm{v} / \mathrm{v})$ in the mixtures. After phagocytosis, the mixtures were washed by centrifuging three times to remove free bacteria. Cells were disrupted with $0.25 \%(\mathrm{w} / \mathrm{v})$ sodium dodecyl sulphate (SDS) and viable bacteria in the suspension were counted. Such a concentration of SDS did not affect the growth of the bacteria (unpublished results). To observe the rate of intracellular killing, cell suspensions were incubated for $30 \mathrm{~min}$ after phagocytosis and washing. The numbers of bacteria remaining viable within cells were determined by culture on nutrient agar after disrupting the cells with SDS.

Histology. Right and left thigh muscles of antiserum-treated mice were each inoculated with $1 \times 10^{5}$ viable $K$. pneumoniae. Infected muscle of the left thigh was removed and the number of viable bacteria was counted $3 \mathrm{~h}, 6 \mathrm{~h}, 24 \mathrm{~h}$ and $72 \mathrm{~h}$ after inoculation. Infected muscle of the right thigh was removed for histological examination at the same times. Sections were stained with haematoxylin and eosin. 


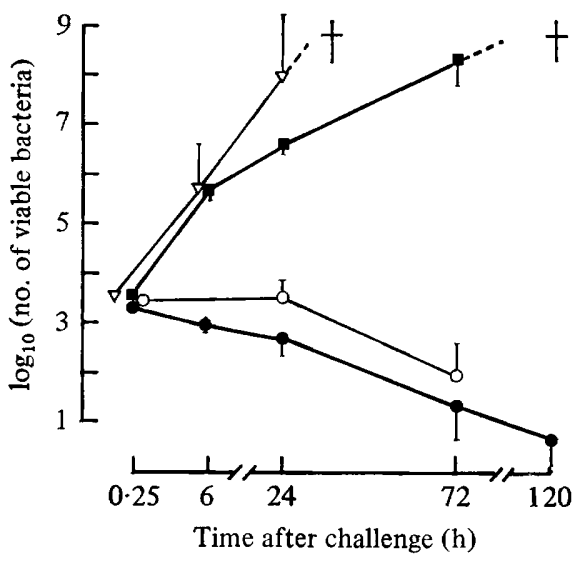

Fig. 1. Bacterial growth in the muscle of mice treated with antiserum (control) (O), normal serum $(\square)$ or carrageenan and antiserum $(O)$, and of X-irradiated mice treated with antiserum $(\nabla)$, after intramuscular inoculation of $1 \times 10^{4} \mathrm{~K}$. pneumoniae. Each point and bar indicate the mean result for five animals with the standard error. $\dagger$ indicates mice died.

\section{RESULTS}

\section{Effect of antiserum on $K$. pneumoniae-inoculated mice and on bacterial} growth in carrageenan-treated and $X$-irradiated mice

Mice pretreated with antiserum were protected completely from an intramuscular challenge with $1 \times 10^{7} \mathrm{~K}$. pneumoniae, although the mortality of normal mice inoculated with $10 \mathrm{~K}$. pneumoniae was $80 \%$. Viable bacteria in infected muscle from groups of five mice were counted after intramuscular inoculation of $1 \times 10^{4} \mathrm{~K}$. pneumoniae. In the antiserumtreated control mice, numbers of the bacteria decreased progressively over $120 \mathrm{~h}$ to reach an almost undetectable level (Fig. 1). No bacteria were detected in the liver and blood throughout the experiment. In mice treated with normal serum, numbers in the muscle increased rapidly by $72 \mathrm{~h}$ to reach over $1 \times 10^{8}$. A few bacteria appeared at $6 \mathrm{~h}$ in the liver and blood and their numbers increased rapidly; none of these mice survived $5 \mathrm{~d}$ after infection. Bacterial numbers decreased by $72 \mathrm{~h}$ in antiserum- and carrageenan-treated mice, similar to the decrease in antiserum-treated control mice. In antiserum-treated X-irradiated mice, the numbers increased markedly by $24 \mathrm{~h}$ to reach more than $1 \times 10^{7}$; none of these mice survived $48 \mathrm{~h}$ after infection.

The degree of elimination of inoculated $K$. pneumoniae was compared with that of $P$. aeruginosa, which is killed by phagocytes effectively and rapidly (Tatsukawa et al., 1979). When $1 \times 10^{5} P$. aeruginosa were inoculated into untreated control mice, the $\log _{10}$ of the number of bacteria recovered from the muscle $15 \mathrm{~min}$ after inoculation was $4 \cdot 96 \pm$ s.e. 0.09, decreasing rapidly by $24 \mathrm{~h}$ to reach $2 \cdot 79 \pm 0 \cdot 27$. The number decreased in carrageenantreated mice in the same way as in control mice. The degree of elimination of $P$. aeruginosa in the absence of antiserum was apparently greater than that of $K$. pneumoniae in the presence of antiserum.

Growth of $K$. pneumoniae in the muscle of nude mice in the presence of antiserum

To observe the effect of the presence of the thymus on the elimination of inoculated $K$. pneumoniae, athymic nu/nu and control nu/ + mice were inoculated with $1 \times 10^{4} \mathrm{~K}$. pneumoniae. Viable bacteria in the infected muscle from five antiserum-treated mice of each group were counted. The $\log _{10}$ of the numbers of bacteria in $\mathrm{nu} / \mathrm{nu}$ and $\mathrm{nu} /+$ mice $6 \mathrm{~h}$ after inoculation were $3 \cdot 06 \pm 0 \cdot 10$ and $3 \cdot 10 \pm 0 \cdot 17$, respectively; no significant difference was observed between $\mathrm{nu} / \mathrm{nu}$ and $\mathrm{nu} /+$ mice. 


\section{Phagocytosis and intracellular killing of bacteria in vitro}

In the presence of antiserum, $1.63 \times 10^{6} \mathrm{~K}$. pneumoniae were phagocytized by $1 \times 10^{7}$ macrophages. The degree of phagocytosis by PMN was about eightfold lower than that by macrophages. Unphagocytized bacteria could not be removed completely by washing three times, and small numbers of these were counted as phagocytized bacteria. When allowance was made for this source of error, macrophages or PMN seemed to be almost unable to phagocytize $K$. pneumoniae in the absence of antiserum. Approximately one-half of the phagocytized $K$. pneumoniae were killed by PMN or macrophages during 30 min incubation in the presence of antiserum.

In the absence of antiserum, $8.7 \times 10^{5}$ and $1.7 \times 10^{5} P$. aeruginosa were phagocytized by $1 \times 10^{7}$ macrophages and $1 \times 10^{7} \mathrm{PMN}$, respectively. The degree of intracellular killing of $P$. aeruginosa by macrophages or PMN in the absence of antiserum was about fourfold greater than that of $K$. pneumoniae in the presence of antiserum.

\section{Bacterial growth in the muscle and histological examination of cellular infiltration into infected sites in antiserum-treated mice}

At $15 \mathrm{~min}$ after inoculation with $1 \times 10^{5} \mathrm{~K}$. pneumoniae, the $\log _{10}$ of the number of bacteria recovered from the muscle from five mice was $4 \cdot 73 \pm 0 \cdot 06$. Slight cellular infiltration by PMN was observed at $3 \mathrm{~h}$, when the $\log _{10}$ of the number of bacteria had reached $5 \cdot 71 \pm$ $0 \cdot 10$. The $\log _{10}$ of the number then decreased to reach $4 \cdot 78 \pm 0 \cdot 48$ at $6 \mathrm{~h}$, at which time marked cellular infiltration was observed. Approximately $95 \%$ of the infiltrating cells observed were PMN. Bacterial numbers decreased by $72 \mathrm{~h}$, but the degree of cellular infiltration remained approximately constant. The proportion of macrophages and lymphocytes increased progressively from 24 to $72 \mathrm{~h}$ and these cells comprised about $85 \%$ of the infiltrating cells observed at $72 \mathrm{~h}$.

\section{DISCUSSION}

No significant phagocytosis of $K$. pneumoniae by PMN or macrophages was observed in vitro in the absence of antiserum. In vivo, inoculated $K$. pneumoniae was virulent. Klebsiella pneumoniae inoculated intramuscularly without antiserum grew progressively until the mice died. Systemic spread of bacteria occurred soon after inoculation. On the other hand, $K$. pneumoniae inoculated into antiserum-treated mice remained localized within the inoculated muscle and were finally eliminated.

Carrageenan may be used to block selectively the functioning mononuclear phagocytes (Tatsukawa et al., 1979). On the other hand, the numbers of both PMN and monocytes decreased markedly in X-irradiated mice (unpublished results). Therefore, carrageenantreated mice may be regarded as macrophage-depleted and X-irradiated mice as PMN- and monocyte-depleted. Although $K$. pneumoniae was eliminated efficiently in controls given antiserum, progressive growth of bacteria was observed in X-irradiated mice even in the presence of antiserum. Thus, antiserum had no significant direct bactericidal effect against $K$. pneumoniae; its protective effect depended on radiosensitive cells, including both phagocytes and lymphocytes. However, $\mathrm{T}$ lymphocytes appeared not to affect protection against $K$. pneumoniae in the presence of antiserum at an early phase of infection, because $K$. pneumoniae was eliminated in athymic nude mice as efficiently as in normal littermates. We conclude that the main effect of antiserum was opsonization for phagocytosis.

To obtain more information, protection against $K$. pneumoniae was compared with that against $P$. aeruginosa. Pseudomonas aeruginosa inoculated into muscle is known to be eliminated efficiently by PMN even in the absence of macrophages (Tatsukawa et al., 1979). Growth patterns of $K$. pneumoniae in the presence of antiserum in carrageenan-treated mice 
and normal controls are fundamentally similar to those of $P$. aeruginosa in the absence of antiserum. It was concluded tentatively that $K$. pneumoniae inoculated in the presence of antiserum was killed effectively by PMN even in the absence of normally functioning macrophages.

In antiserum-treated mice, the number of bacteria started to decrease at $6 \mathrm{~h}$, when marked infiltration of PMN was observed, but only very small numbers of macrophages were observed. The rate of phagocytosis of $K$. pneumoniae by macrophages in the presence of antiserum in vitro was greater than that by PMN, and macrophages killed $K$. pneumoniae as efficiently as did PMN. These results suggest that PMN protect efficiently against $K$. pneumoniae by their rapid accumulation at infected sites even in the absence of macrophages, although the latter may also contribute.

Dependence of protection on antiserum and relative resistance to intracellular killing by phagocytes may account for some of the pathogenicity of opportunistic infection by members of encapsulated Klebsiella species for immunologically impaired or otherwise susceptible patients.

\section{REFERENCES}

Catanzaro, P. J., Schwartz, H. J. \& Graham, R. C. (1971). Spectrum and possible mechanism of carrageenan cytotoxicity. American Journal of Pathology 64, 387-399.

Dreizen, S., Bodey, G. P. \& Brown, L. R. (1974). Opportunistic Gram-negative bacillary infections in leukemia. Oral manifestations during myelosuppression. Postgraduate Medicine 55, 133139.

Graybill, J. R., Marshall, L. W., Charache, P., Wallace, C. K. \& Melvin, V. B. (1973). Nosocomical pneumonia, a continuing major problem. American Review of Respiratory Disease 108, 1130-1140.

Julianelle, L. A. (1926). A biological classification of encapsulatus pneumoniae (Friedländer's bacillus). Journal of Experimental Medicine 44, 113-128.
Lorian, V. \& ToPf, B. (1972). Microbiology of nosocomical infections. Archives of Internal Medicine 130, 104-110.

Mitsuyama, M., Takeya, K., Nomoto, K. \& Shimotori, S. (1978). Three phases of phagocyte contribution to resistance against Listeria monocytogenes. Journal of General Microbiology 106, 165-171.

Tatsukawa, K., Mitsuyama, M., Takeya, K. \& Nomoto, K. (1979). Differing contribution of polymorphonuclear cells and macrophages to protection against Listeria monocytogenes and Pseudomonas aeruginosa. Journal of General Microbiology 115, 161-166.

Van Furth, R., Van Zwet, T. L. \& Leijh, P. C. (1978). In Handbook of Experimental Immunology, 2nd edn, ch. 32. Edited by D. M. Weir. Oxford: Blackwell Scientific Publications. 